Arq. Bras. Med. Vet. Zootec., v.65, n.2, p.346-352, 2013

\title{
Avaliação morfológica do abomaso e ceco-cólon de bovinos
}

\author{
[Morphologic evaluation of the abomasum and cecum-colon of bovines] \\ M.G. Cardoso ${ }^{1}$, J.C. Resende Júnior ${ }^{2 *}$, R.F. Lima ${ }^{1}$, J.L.P. Daniel ${ }^{3}$ \\ ${ }^{1}$ Aluno de pós-graduação - Universidade Federal de Lavras - Lavras, MG \\ ${ }^{2}$ Universidade Federal de Lavras - Lavras, MG \\ ${ }^{3}$ Universidade de São Paulo - Escola Superior de Agricultura Luiz de Queiroz - Piracicaba, SP
}

\begin{abstract}
RESUMO
A morfofisiologia relacionada à absorção de ácidos graxos voláteis (AGV) ao longo do trato gastrintestinal de ruminantes não é totalmente caracterizada. Desse modo, os objetivos deste trabalho foram mensurar a extensão da superfície de absorção e determinar o índice mitótico (IM) do abomaso, do ceco e da alça proximal do cólon ascendente (APCA). Dez bovinos mestiços adultos tiveram seu estômago e intestino grosso removidos imediatamente após o abate. A área total da superfície de absorção foi mensurada por meio de digitalização e análise de imagens. Cortes histológicos foram feitos para determinação do IM. A superfície absortiva do abomaso, $0,58 \mathrm{~m}^{2}$, foi menor $(P<0,01)$ do que a do rúmen, $6,53 \mathrm{~m}^{2}$, e a do omaso, $2,31 \mathrm{~m}^{2}$. A superfície absortiva do ceco e da APCA, $0,23 \mathrm{~m}^{2}$, correspondeu a $3,5 \%$ da superfície do rúmen e a $10 \%$ da superfície do omaso. O IM observado foi $0,48 \% ; 0,14 \% ; 0,36 \%$ e $0,41 \%$ para as regiões de pregas espirais, pilórica, ceco e APCA, respectivamente. Observou-se correlação positiva entre a massa tecidual do abomaso e a área de superfície de absorção, aspecto também observado no ceco-APCA. Foi possível estabelecer regressões para facilitar a mensuração da superfície absortiva do abomaso e do ceco-APCA.
\end{abstract}

Palavras-chave: ruminante, câmara de fermentação distal, estômago, índice mitótico, intestino grosso, absorção

\begin{abstract}
The morphology and physiology related to volatile fatty acid (VFA) absorption throughout the gastrointestinal tract of ruminants is not totally characterized. The purpose of this work was to measure the abomasum and cecum-colon absorptive surface extension and determine the mitotic index (MI). Ten adult crossbred bovine had their stomach and large intestine removed after slaughter. The total area of the absorptive surface was measured through image capture and analysis. Histological sections were performed to measure the MI. The abomasum absorptive surface $\left(0.58 \mathrm{~m}^{2}\right)$ was lower $(P<0.01)$ than that of the rumen $\left(6.53 \mathrm{~m}^{2}\right)$ and omasum $\left(2.31 \mathrm{~m}^{2}\right)$. The cecum-colon absorptive surface $\left(0.23 \mathrm{~m}^{2}\right)$ corresponded to $3.5 \%$ of the rumen and $10 \%$ of the omasum. The MI observed was $0.48 \% ; 0.14 \% ; 0.36 \%$ and $0.41 \%$ for the regions of spiral folds, pyloric, cecum and proximal loop of ascending colon, respectively. A positive correlation between abomasum tissue mass and the abomasum absorptive surface was observed. This phenomenon has also occurred in the cecum and colon. It was possible to establish regressions to facilitate measurements of the absorptive surface of the abomasum and cecum-colon.
\end{abstract}

Keywords: ruminant, distal fermentation chamber, stomach, mitotic index, large intestine, absorptive surface

Recebido em 28 de setembro de 2011

Aceito em 1 de outubro de 2012

*Autor para correspondência (corresponding author)

E-mail: joaocrj@dmv.ufla.br 


\section{INTRODUÇÃO}

Os ácidos graxos voláteis (AGV) produzidos no trato gastrintestinal (TGI) como subprodutos do metabolismo microbiano podem prover até $80 \%$ da exigência diária de energia dos ruminantes (Bergman, 1990). Ao longo do TGI as maiores concentrações de AGV ocorrem no ruminorretículo e no ceco-cólon (Elsden et al., 1946).

No ruminorretículo a remoção (clearance) dos AGV ocorre por dois processos: absorção pela parede do órgão e passagem para o omaso juntamente com a fase fluida ruminal (Peters et al., 1990). A maior parte clearance ruminal de AGV acontece por absorção pela parede do ruminorretículo, mas, conforme a dieta e a IMS, cerca de 30 (Voelker e Allen, 2003) a 45\% (Resende Júnior et al., 2006b) passam para o omaso, que parece absorver a maioria dos AGV que a ele chegam. Porém, quantidade considerável de AGV pode atingir o abomaso, já que 7 a $14 \mathrm{mM}$ de $A G V$ podem atingir o duodeno (Rupp et al., 1994). O excesso de AGV na digesta abomasal pode causar hipomotilidade do órgão (Bolton et al., 1976), a qual consiste em um dos fatores predisponentes ao deslocamento de abomaso em bovinos (Svendsen, 1969).

O ceco e a alça proximal do cólon ascendente (APCA), segmentos anatômicos do intestino grosso, também são sítios de produção e absorção de AGV. A produção ceco-cólica de AGV contribui com aproximadamente dez por cento da energia metabolizável absorvida diariamente pelos ruminantes (Siciliano-Jones e Murphy, 1989). Apesar de a produção e a remoção de AGV serem distribuídas, embora não equitativamente, em várias regiões do TGI, a maioria do conhecimento gerado envolve o ruminorretículo. A superfície absortiva do ruminorretículo e do omaso de bovinos já é conhecida (Daniel et al., 2006) bem como suas correlações com as taxas fracionais de absorção de AGV (Daniel e Resende Júnior, 2012). Entretanto, essas informações são desconhecidas em relação ao abomaso e ao ceco-cólon de bovinos, apesar de o diâmetro e o comprimento desses segmentos já serem conhecidos há bastante tempo (Nickel et al., 1979). O índice mitótico é considerado um dos melhores marcadores morfológicos de proliferação do epitélio do rúmen (Resende Júnior et al., 2006a) e já foram estabelecidas correlações entre o IM e as taxas fracionais de absorção e metabolização de $A G V$ no rúmen e omaso (Daniel e Resende Júnior, 2012).

Com o presente experimento objetivou-se medir a superfície de absorção e o IM do abomaso e do ceco-APCA de bovinos.

\section{MATERIAL E MÉTODOS}

Dez bovinos mestiços adultos, de ambos os sexos, com média de peso corporal de $459,5 \pm 50,7 \mathrm{~kg}$, com alimentação desconhecida, provenientes de um matadouro comercial, tiveram o estômago e o intestino grosso removidos imediatamente após o abate. Abomaso, ceco e APCA foram separados, acondicionados em caixas isotérmicas e encaminhados a um laboratório de anatomia veterinária. Um fragmento do saco ventral do rúmen foi retirado a $10 \mathrm{~cm}$ do pilar cranial, armazenado em solução tampão fosfato (PBS = $0,068 \mathrm{~g} \mathrm{KH}_{2} \mathrm{PO}_{4} ; 0,283 \mathrm{~g} \mathrm{NaH}_{2} \mathrm{PO}^{4} ; 8,5 \mathrm{~g} \mathrm{NaCl}$; $1000 \mathrm{ml} \mathrm{H}_{2} \mathrm{O}$ ) e resfriado, para posterior estimativa da superfície total do rúmen. O peso do omaso vazio foi reportado.

No laboratório, o tecido conjuntivo excedente da superfície externa dos órgãos foi removido, e o peso de cada segmento anatômico, registrado. O abomaso foi dividido em região de pregas espirais e região pilórica; o ceco-cólon foi dividido em ceco e APCA, tomando como referência a papila ileal. Fragmentaram-se as regiões de maneira a possibilitar a digitalização de suas imagens através de um scanner (ScanAce 630p, Pacific Image Electronics ${ }^{\circledR}$ ). Ao lado dos fragmentos era colocada um escala de $1 \mathrm{~cm}$ para permitir posterior calibração das imagens. As áreas foram estimadas através do programa de análise de imagens UTHSCSA Image Tool (software livre), como proposto por Resende Júnior et al. (2006a).

Para determinar a superfície absortiva total do abomaso, assumiu-se a espessura da base das pregas como valor médio $(0,1 \mathrm{~cm})$, estimado por meio de paquímetro. A superfície absortiva total do abomaso foi calculada pela seguinte equação: Superfície absortiva $=$ superfície de parede + superfície das pregas - superfície da base das pregas. A superfície absortiva do ceco e da APCA foi dada pela área de parede dos órgãos, 
pois estes não possuem projeções. O número de papilas contidas no fragmento coletado do rúmen foi obtido e 12 papilas foram seccionadas aleatoriamente. Digitalizaram-se as papilas e o fragmento para determinação da superfície absortiva do rúmen através de regressão proposta por Daniel et al. (2006). O peso do omaso sem digesta foi utilizado para determinar a superfície absortiva do omaso de acordo com a seguinte equação de regressão $\left(r^{2}=0,71 ; P=0,02\right)$ : Área total da superfície do omaso $\left(\mathrm{cm}^{2}\right)=7,12 *$ peso do omaso sem digesta (g) - 756,04 (Daniel, 2007, Universidade Federal de Lavras, comunicação pessoal).

Após a digitalização, foi mensurado o peso da mucosa + submucosa e do restante da parede da região das pregas espirais depois de dissecadas. A região pilórica do abomaso, o ceco e a APCA tiveram um fragmento de $25 \mathrm{~cm}^{2}$ isolado, e o peso da mucosa + submucosa e do restante da parede foram reportados.

A determinação do IM foi realizada em lâminas coradas pela hematoxilina - eosina. No abomaso o IM foi determinado no epitélio de revestimento das fossetas gástricas e no epitélio glandular das regiões de pregas espirais e pilórica. No ceco e na APCA, o IM foi determinado no epitélio das glândulas intestinais. Os núcleos de 4000 células foram contabilizados em todas as regiões em que as fossetas e glândulas gástricas e intestinais estavam bem definidas. Para essa contagem, utilizou-se um microscópio óptico (Ernst Leitz Wetzlar Nr. 438895, Germany) em um aumento de 400 vezes. Todas as células que apresentaram núcleo com figuras mitóticas foram contabilizadas. O percentual do IM foi calculado dividindo-se o número de células apresentando figuras mitóticas pelo número total de núcleos contados. Três avaliadores independentes fizeram a contagem de células em cada fragmento, e o número médio entre as três avaliações foi utilizado como resultado.

Para análise dos dados adotou-se o delineamento blocos ao acaso, no qual cada animal foi considerado como um bloco. A superfície absortiva total, a superfície absortiva de parede, a superfície absortiva de projeções (pregas), o peso do órgão, o peso da mucosa + submucosa, a razão peso de mucosa + submucosa : peso do restante da parede e o IM dos órgãos foram analisadas pelo procedimento GLM do pacote estatístico SAS (Statistical, 1999). Estabeleceram-se correlações pelo procedimento CORR do SAS, e regressões lineares foram desenvolvidas com o procedimento REG do SAS. As médias foram comparadas uma a uma pelo teste Tukey.

\section{RESULTADOS E DISCUSSÃO}

Apesar de estar descrito na literatura que, no bovino, o tamanho do abomaso é superior ao do omaso (Nickel et al., 1979), a sua superfície absortiva é menor (Tab. 1), especialmente devido à grande área proporcionada pelas lâminas do omaso. Então, a ordem decrescente entre as superfícies absortivas dos compartimentos do estômago é rúmen, omaso, abomaso e retículo, considerando a área reticular estimada por Daniel et al. (2006).

Tabela 1. Peso do órgão e superfície de absorção por região anatômica do estômago de bovinos adultos

\begin{tabular}{lccccccc} 
& Rúmen & Omaso & Abomaso & $\begin{array}{c}\text { Pregas } \\
\text { espirais }\end{array}$ & $\begin{array}{c}\text { Região } \\
\text { Pilórica }\end{array}$ & EPM $^{1}$ & $P$ \\
\hline Peso órgão $(\mathrm{kg})$ & - & $3,2 \mathrm{a}$ & $1,4 \mathrm{~b}$ & - & - & 0,12 & $<0,01$ \\
$\begin{array}{l}\text { Superfície absortiva do } \\
\text { compartimento }\left(\mathrm{m}^{2}\right)\end{array}$ & $6,5 \mathrm{a}$ & $2,3 \mathrm{~b}$ & $0,6 \mathrm{c}$ & - & - & 0,21 & $<0,01$ \\
\begin{tabular}{l} 
Superfície absortiva por região $\left(\mathrm{m}^{2}\right)$ \\
\hline
\end{tabular} & - & - & - & $0,53 \mathrm{a}$ & $0,05 \mathrm{~b}$ & 0,03 & $<0,01$ \\
\hline
\end{tabular}

${ }^{1}$ Erro padrão da média.

Médias seguidas de letras distintas na linha diferem entre si pelo Teste Tukey $(P<0,05)$.

Houve alta correlação positiva $\left(\mathrm{r}^{2}=0,85 ; P<0.01\right)$ entre a superfície absortiva e o peso do abomaso sem digesta. Em vacas leiteiras no período periparto foi observada variação da massa dos tecidos viscerais (Reynolds et al., 2004). Os autores detectaram aumento do peso do abomaso $(P=0,06)$ aos 22 dias de lactação, quando os animais mudaram de uma dieta de transição para 
uma dieta de lactação. Então, existem indícios de que a superfície absortiva do abomaso pode responder a diferentes níveis de energia da dieta, provavelmente refletindo diferentes concentrações de AGV que chegam ao órgão.

O coeficiente de correlação encontrado permite a estimativa da superfície do abomaso por meio do peso do órgão sem digesta, podendo facilitar a metodologia de futuros experimentos, de acordo com a seguinte equação: Área total da superfície do abomaso $=2,9704 *$ peso do abomaso sem digesta $+1685,51$.

Também foi encontrado alto coeficiente de correlação $\left(\mathrm{r}^{2}=0,99 ; P<0,01\right)$ entre o peso da mucosa e submucosa do abomaso e a extensão da superfície absortiva, tornando possível a estimativa da área total do abomaso utilizando-se a seguinte equação: Área total $\left(\mathrm{cm}^{2}\right)$ da superfície do abomaso $=7,94308 *$ peso $(\mathrm{g}) \mathrm{da}$ mucosa + submucosa do abomaso + 471,32399. Outra possibilidade é utilizar apenas o peso da mucosa e da submucosa das pregas espirais pela seguinte equação $\left(\mathrm{r}^{2}=0,94 ; P=0.01\right)$ : Área total $\left(\mathrm{cm}^{2}\right)$ da superfície do abomaso $=10,75954 *$ peso (g) da mucosa + submucosa das pregas espirais $+1584,34196$.

As superfícies absortivas do ceco e da APCA foram similares (Tab. 2). A superfície absortiva do ceco-cólon representou aproximadamente $3,5 \%$ da superfície do rúmen e $10 \%$ da superfície do omaso. Apesar de a literatura mostrar que o ceco-cólon apresenta uma capacidade de armazenamento de digesta que corresponde a $10 \%$ da capacidade do rúmen (Getty, 1981), a metodologia utilizada para se obter a capacidade dos órgãos foi baseada no volume destes, sendo, portanto, diferente da utilizada no presente trabalho para se obter a superfície absortiva. Apesar dessa pequena proporção em relação aos compartimentos do estômago, no estudo de Siciliano-Jones e Murphy (1989), o ceco-cólon contribuiu, em média, com $8,6 \%$ da produção de energia metabolizável (EM) total, enquanto que o ruminorretículo contribuiu em média com $62 \%$. A proporção entre a produção de energia metabolizável obtida por Siciliano-Jones e Murphy (1989) e a superfície absortiva obtida no presente estudo (\% de produção de EM $/ \mathrm{m}^{2}$ de superfície absortiva) é aproximadamente quatro vezes maior no ceco-cólon do que no rúmen.

Tabela 2. Superfície absortiva total do rúmen e do ceco-cólon e superfície absortiva das regiões do cecocólon de bovinos adultos

\begin{tabular}{lcccccc} 
& Rúmen & Ceco-cólon & Ceco & APCA & EPM & $P$ \\
\hline $\begin{array}{l}\text { Superfície absortiva } \\
\text { compartimento }\left(\mathrm{m}^{2}\right)\end{array}$ & 6,53 & 0,23 & - & - & 0,26 & $<0,01$ \\
$\begin{array}{l}\text { Superfície absortiva por } \\
\text { região }\left(\mathrm{m}^{2}\right)\end{array}$ & - & - & 0,11 & 0,12 & 0,004 & 0,26 \\
\end{tabular}

APCA: Alça proximal do cólon ascendente.

EPM: Erro padrão da média.

Quando a taxa de produção excede a taxa de absorção de ácidos orgânicos na câmara de fermentação, há aumento da osmolaridade com consequente influxo de água para o lúmen do órgão. Como a taxa de produção de ácidos orgânicos depende da disponibilidade de substratos, a consistência das fezes pode ser utilizada como um bom indicador do escape ruminal de partículas potencialmente fermentáveis (Wheeler e Noller, 1977; Depenbusch et al., 2008), pois o aumento da concentração de substratos no intestino grosso leva ao influxo de água e consequentemente ao amolecimento das fezes.

No ceco e APCA também é possível estimar a superfície absortiva pelo peso desses segmentos anatômicos; entretanto, por uma equação com coeficiente de correlação mais baixo $\left(\mathrm{r}^{2}=0,60\right.$; $P=0,01)$ : Área total $\left(\mathrm{cm}^{2}\right)$ da superfície absortiva do ceco e APCA $=1,936 *$ peso $(\mathrm{g})$ do ceco + APCA sem digesta $+703,492$. 
O fato de ter sido possível detectar correlações com $\mathrm{r}^{2}$ mais alto nas regiões do abomaso pode ser explicado pela proporção entre o peso de mucosa + submucosa e o restante da parede ser de 2,1 na região de pregas espirais. Esse valor é bem maior do que o valor encontrado para a proporção entre a mucosa + submucosa e o restante da parede do ceco $(0,7)$ e da APCA $(0,84)$. Isso indica que a massa tecidual do abomaso reflete mais a superfície absortiva desse órgão do que no caso do ceco e APCA.

O maior IM na mucosa do abomaso $(0,48 \%)$, na região de pregas espirais, indica maior proliferação de células $(\mathrm{P}<0,01)$ quando comparado ao IM da região pilórica do abomaso $(0,13 \%)$. Isso é resultante de uma maior taxa de renovação celular (Samuelson, 2007) e pode refletir uma maior absorção de AGV, como é observado no rúmen (Sakata e Tamate, 1976; Gálfi et al., 1986). A região de pregas espirais corresponde a $91 \%$ da superfície absortiva do abomaso, demonstrando maior importância dessa região na absorção dos AGV que eventualmente chegam ao compartimento. O IM entre as duas regiões do abomaso mostrou correlação positiva e alta $(0,81, \mathrm{P}<0,05)$, indicando que os fatores estimuladores da proliferação da mucosa devem ser os mesmos para o órgão como um todo. Já os IM do ceco $(0,36 \%)$ e da APCA $(0,42 \%)$ não apresentaram diferenças significativas entre si e não foram correlacionados. No entanto, não é seguro inferir que as variações de IM nesses órgãos não dependem dos mesmos fatores. Certamente será necessário um experimento com amostragem maior para se estabelecer a relação dessa variável entre esses órgãos.

As concentrações de AGV e pH do fluido provocam alterações na taxa fracional de absorção de AGV (Dijkstra et al., 1993) e no IM (Sakata e Tamate, 1976; Gálfi et al., 1986) do epitélio ruminorreticular. O mesmo parece ocorrer no ceco-cólon. Myers et al. (1967), ao isolar o ceco de carneiros e fazer infusões de AGV através de uma cânula, implantada cirurgicamente, observaram alterações na taxa fracional de absorção quando houve alterações no $\mathrm{pH}$ do fluido e nas concentrações de AGV. A influência da dieta e de infusões diretas de AGV no IM, no peso de mucosa e no tamanho das criptas já foi demonstrada no ceco e APCA de ratos (Sakata e Engelhardt, 1983; Sakata, 1987; Edwards et al., 1992; Ichikawa e Sakata, 1997) e, provavelmente, o mesmo deve ocorrer no cecocólon de ruminantes. Entretanto, pesquisas que demonstrem essa inferência não foram encontradas na literatura. Por outro lado, há de se considerar que o aporte de energia para a câmara de fermentação distal varia principalmente com fatores relacionados ao manejo alimentar. Sendo assim, dietas mais energéticas não levariam necessariamente ao maior aporte de matéria orgânica fermentável no ceco e APCA, resultando em maior concentração de AGV. Contudo, existe o fato de que a proliferação epitelial induzida por AGV tem o envolvimento de fatores indiretos, como insulina (Sakata et al., 1980) e IGF-1 (Shen et al., 2004). Daniel e Resende Júnior (2012), ao trabalharem in vitro com fragmentos de estômago de bovinos, encontraram correlação positiva e alta entre IM e taxa fracional de absorção no omaso, mas não no rúmen. $\mathrm{O}$ conhecimento desse comportamento na câmara de fermentação distal traria um incremento importante nessa área de conhecimento.

\section{CONCLUSÕES}

A superfície absortiva do abomaso e ceco-cólon é menor que a do rúmen e do omaso. No entanto, o significado dessa informação na cinética de absorção de AGV é obscuro até que se elucidem os parâmetros fisiológicos envolvidos. Foi possível estabelecer equações de regressão que podem facilitar metodologicamente trabalhos posteriores que necessitem da mensuração da superfície absortiva dos órgãos estudados.

\section{AGRADECIMENTO}

Os autores agradecem à Fundação de Amparo à Pesquisa do Estado de Minas Gerais FAPEMIG - pelo financiamento da pesquisa. 


\section{REFERÊNCIAS}

BERGMAN, E.N. Energy contributions of volatile fatty acids from the gastrointestinal tract in various species. Physioll. Rev., v.70, p.567590,1990

BOLTON, J.R.; MERRIT, A.M.; CARLSON, G.M. et al. Normal abomasal electromyography and emptying in sheep and the effects of intraabomasal volatile fatty acid infusion. Am. $J$. Vet. Res., v.37, p.1387-1392, 1976.

DANIEL, J.L.P.; RESENDE JUNIOR, J.C. Absorption and metabolism of volatile fatty acids by rumen and omasum. Cienc. Agrotec., v.36, p.93-99, 2012.

DANIEL, J.L.P.; RESENDE JÚNIOR, J.C.; CRUZ, F.J. Participação do ruminorretículo e omaso na superfície absortiva total do proventrículo de bovinos. Braz. J. Vet. Res. Anim. Sci., v.43, p.688-694, 2006.

DEPENBUSCH, B.E.; NAGARAJA, T.G.; SARGEANT, J.M. et al. Influence of processed grains on fecal $\mathrm{pH}$, starch concentration, and shedding of Escherichia coli O157 in feedlot cattle. J. Anim. Sci., v.86, p.632-639, 2008.

DIJKSTRA, J.; BOER, H.; VAN BRUCHEM, J. et al. Absorption of volatile fatty acids from the rumen of lactating dairy cows as influenced by volatile fatty acid concentration, $\mathrm{pH}$ and rumen liquid volume. Br. J. Nutr., v.69, p.385-396, 1993.

EDWARDS, C.A.; WILSON, R.G.; HANLON, L. et al. Effect of the dietary fiber content of lifelong diet on colonic cellular proliferation in the rat. Gut., v.33, p.1076-1079, 1992.

ELSDEN, S.R.; HITCHCOCK, M.W.S.; MARSHALL, R.A. et al. Volatile acid in the digesta of ruminants and other animals. J. Exp. Biol., v.22, p.191-202, 1946.

GÁLFI, P.; NEOGRÁDY, S.; KUTAS, F. Dissimilar ruminal epithelial response to shortterm and continuous intraruminal infusion of sodium n-butyrate. Zentralbl. Vet., v.33, p.47-52, 1986.

GETTY, R. Sisson e Grossman anatomia dos animais domésticos. 5.ed. Rio de Janeiro: Interamericana, 1981. 2000p.
ICHIKAWA, H.; SAKATA, T. Effect of L-lactic Acid, short-chain fatty acids, and $\mathrm{pH}$ in cecal infusate on morphometric and cell kinetic parameters of rat cecum. Dig. Dis. Sci., v.42, p.1598-1610, 1997.

MYERS, L.L.; JACKSON, H.D.; PACKETT, L.V. Absorption of volatile fatty acids from the cecum of sheep. J. Anim. Sci., v.26, p.1450-1458, 1967.

NICKEL, R.; SCHUMMER, A.; SEIFERLE, E. The viscera of the domestic mammals. 2. ed. rev. Berlim; Hamburg: Verlag Paul Parey, 1979. v.2. 403p.

PETERS, J.P.; SHEN, R.Y.W.; CHESTER, S.T. Propionic acid disappearance from the foregut and small intestine of the beef steer. J. Anim. Sci., v.68, p.3905-3913, 1990.

REYNOLDS, C.K.; DÜRST, B.; LUPOLI, B. et al. Visceral tissue mass and rumen volume in dairy cows during the transition from late gestation to early lactation. J. Dairy Sci., v.87, p.961-971, 2004.

RESENDE JÚNIOR, J.C.; ALONSO, L.S.; PEREIRA, M.N. et al. Effect of the feeding pattern on rumen wall morphology of cows and sheep. Braz. J. Vet. Res. Anim. Sci., v.43, p.526536, 2006a.

RESENDE JÚNIOR, J.C.; PEREIRA, M.N.; BÔER, H. et al. Comparison of techniques to determine the clearance of ruminal volatile fatty acids. J. Dairy Sci., v.89, p.3096-3106, 2006b.

RUPP, G.P.; KREIKEMEIER, K.K.; PERINO, L.J. et al. Measurement of volatile fatty acid disappearance and fluid flux across the abomasum of cattle, using an improved omasal cannulation technique. Am. J. Vet. Res., v.55, p.522-529, 1994.

SAKATA, T. Stimulatory effect of short chain fatty acids on the epithelial cell proliferation in rat large intestine: a possible explanation for trophic effects of fermentable fiber, gut microbes and luminal trophic factors. Br. J. Nutr., v.58, p.95-103, 1987.

SAKATA, T.; ENGELHARDT, W.V. Stimulatory effect of short chain fatty acids on the epithelial cell proliferation in rat large intestine. Comp. Biochem. Physiol., Part A, v.74, p.459-462, 1983. 
SAKATA, T.; HIKOSAKA, K.; SHIOMURA, Y. et al. Stimulatory effect of insulin on ruminal epithelium cell mitosis in adult sheep. $B r . J$. Nutr., v.44, p.325-331, 1980.

SAKATA, T.; TAMATE, $H$. Effect of intraruminal injection of n-sodium butyrate on the mitotic indices in sheep ruminal epithelium. Tohoku J. Agr. Res., v.27, p.133-135, 1976.

SAMUELSON, D.A. Tratado de histologia veterinária. 1.ed. Rio de Janeiro: Elsevier, 2007. $527 \mathrm{p}$.

STATISTICAL Analysis System - SAS Institute. SAS/STAT Users Guide. Version 6.12. SAS Institute Inc., Cary, NC. 1999.

SHEN, Z.; SEYFERT, H.M.; LÖHRKE, B. et al. An energy-rich diet causes rumen papillaer proliferation associated with more IGF type 1 receptors and increased plasma IGF-1 concentrations in young goats. J. Nutr., v.34, p.11-17, 2004.
SICILIANO-JONES, J.; MURPHY, M.R. Production of volatile fatty acids in the rumen and cecumcolon of steers as affected by forage:concentrate and forage physical form. J. Dairy Sci., v.72, p.485-492, 1989.

SVENDSEN, P. Etiology and pathogenesis of abomasal displacement in cattle. Nord. Vet. Med., v.21, suppl.1, p.1, 1969.

VOELKER, J.A.; ALLEN, M.S. Pelleted beet pulp substituted for high-moisture corn: 3 . effects on ruminal fermentation, $\mathrm{pH}$, and microbial protein efficiency in lactating dairy cows. J. Dairy Sci., v.86, p.562-3570, 2003.

WHEELER, W.E.; NOLLER, C.H. Gastrointestinal tract $\mathrm{pH}$ and starch in feces f ruminants. J. Anim. Sci., v.44, p.131-135, 1977. 